\title{
Study and Analysis of Dynamic Management Influence Factor in Current Carrying Capacity of Overhead Transmission Lines
}

\author{
Yuanjing Deng ${ }^{1, a^{*}}$, Yu Zhou ${ }^{2, b}$, Kaiquan Xia ${ }^{1, c}, J_{u n} K^{2}{ }^{2, d}$ and Xichun Ren ${ }^{1, e}$ \\ ${ }^{1}$ China Electrical Power Research Institute \\ 100055,Beijing, China \\ ${ }^{2}$ Electric Power Research Institute of State Grid Qinghai Electrical Power Company \\ 810008,Xining, Qinghai, China \\ adeng_yuanjing@163.com, ${ }^{\mathrm{b}} 470368570 @ q q . c o m$, \\ cxiakq@epri.sgcc.com.cn, ${ }^{d}$ kangjun0018@qh.sgcc.com.cn,erxc@epri.sgcc.com.cn
}

\begin{abstract}
Keywords: smart transmission lines; on-line monitoring; current-carrying capacity; influence factor; sensitivity;

Abstract. Dynamic management in current-carrying capacity of overhead transmission line is a significant application in smart grid. Dynamic management technology in current-carrying capacity is to establish measurement information relationship model of conductor temperature, ambient temperature, wind speed, wind direction, sunshine intensity etc parameters on basis of status monitoring of the line. The sensitivity of several factors such as ambient temperature, wind speed, sunshine intensity and parameters of the conductor on current-carrying capacity calculation of the overhead conductor is analyzed through calculation and the key factors affecting maximum current-carrying capacity is found out. The comparison between Specification in our country and calculation model of IEEE and boundary conditions has been studied.
\end{abstract}

\section{Introduction}

Take the ultra-high voltage grid as the backbone network and strong grid with coordination development of the grid at various voltage levels as basis, the smart grid is under construction which highly integrates the modern and advanced sensing measurement technology, communication technology, information technology, computer technology and control technology with the physical grid. The smart transmission lines as an important part of the smart grid is proposed and studied. Dynamic management of current carrying capacity in overhead transmission line is one of the most significant applications in smart transmission line. Dynamic management technology of current-carrying capacity establishes measurement relationship model conductor temperature, ambient temperature, wind speed, wind direction, sunshine intensity etc parameters on basis of real-time monitoring of overhead transmission lines, which provides real-time accurate information about operation status and environment data of the equipment to the operation system.

Further increasing of power load-flow in the developed area will lead to the demand of capacity. Even though finance investment is enough, construction of new overhead transmission lines is not the most effective way to improve power transmission capability. Improving power transmission capability of the current line is a basic way which will improve operation efficiency and also brings benefit to the grid.

Dynamic capacity increasing technology can support the load-flow increase in short time. Provide support to short time over load operation of the line from technical level at peak or N-1 condition of load, avoid or reduce times and duration of fault. The key factors affecting current-carrying capacity in the model through analysis and calculation are proposed in this paper. 


\section{Boundary Conditions For Designing Current-carrying Capacity}

It is specified in GB50545-2010 Code for design of $110 \mathrm{kV}-750 \mathrm{kV}$ overhead power transmission line that following formula can be applied to calculate allowable current-carrying capacity of the conductor.

$$
I=\sqrt{\left(W_{R}+W_{F}-W_{S}\right) / R_{t}^{\prime}}
$$

In which: $I-$ allowable current-carrying capacity ${ }^{(A)}$ of the conductor;

$W_{R}$ - Radiation heat dissipation power $(\mathrm{W} / \mathrm{m})$ of the conductor in unit length;

$W_{F}$ - Convection heat dissipation power $(W / m)$ of the conductor in unit length;

$W_{S}$ - Sunshine heat absorption power $(\mathrm{W} / \mathrm{m})$ of the conductor in unit length;

$R_{t}^{\prime}$ - AC resistance $(\Omega / \mathrm{m})$ of the conductor at allowable temperature;

Calculation formula of radiation heat dissipation power $W_{R}$ :

$$
\left.W_{R}=\pi \cdot D \cdot \varepsilon \cdot S \mid\left(\theta_{d}+273\right)^{4}-\left(\theta_{a}+273\right)^{4}\right]
$$

In which: $D$ - outer diameter of the conductor;

$\varepsilon$ - Radiation heat dissipation coefficient of the conductor surface, it is $0.23 \sim 0.43$ for bright new wire; it is $0.9 \sim 0.95$ for the old wire or wire coated with black anti-corrosion agent;

$S$ - Stefan-Boltzmann constant, $5.67 \times 10^{-8}\left(\mathrm{~W} / \mathrm{m}^{2}\right)$;

$\theta_{d}$ - - Surface temperature of the conductor;

$\theta_{a}$ - Ambient temperature

Calculation formula of convection heat dissipation power $W_{F}$ :

$$
W_{F}=0.57 \cdot \pi \cdot \lambda_{f} \cdot\left(\theta_{d}-\theta_{a}\right) \operatorname{Re}^{0.485}
$$

In which: $\lambda_{f}-$ Heat transfer coefficient $\left(\mathrm{W} / \mathrm{m}^{\circ} \mathrm{C}\right)$ of air layer on surface of the conductor; Re- - Reynolds number.

Calculation formula of sunshine heat absorption coefficient $W_{s}$ :

$$
W_{S}=\alpha \cdot J \cdot D
$$

In which: $\alpha-$ heat absorption coefficient of conductor surface, it is $0.35 \sim 0.46$ for bright new wire; it is $0.9 \sim 0.95$ for the old wire or the wire coated with black anti-corrosion agent.

$J$ - Sunshine strength coefficient $\left(\mathrm{W} / \mathrm{m}^{2}\right)$ of sunlight to the conductor.

When current-carrying capacity of the conductor is calculated, allowable temperature of the steel core aluminum twist wire and the steel core gold twist wire is specified to $70^{\circ} \mathrm{C}$, and $80^{\circ} \mathrm{C}$ can be applied if necessary. Ambient temperature shall apply average maximum temperature in hottest month, it means monthly average value of highest air temperature in every day in hottest month, take average value of several months, solar radiation power density shall apply $1000 \mathrm{~W} / \mathrm{m}^{2}$, and calculation wind speed of the general line shall apply $0.5 \mathrm{~m} / \mathrm{s}$. Because average height of the conductor in the large span is above $30 \mathrm{~m}$, wind speed shall increase accordingly, and it takes $0.6 \mathrm{~m} / \mathrm{s}$. 
Table 1 Boundary conditions of current-carrying capacity in every country

\begin{tabular}{|c|c|c|c|c|c|c|}
\hline Boundary condition & China & Japan & IEC & \multicolumn{4}{|c|}{ British } \\
\cline { 5 - 7 } & & Winter & Summer & Broil area \\
\hline $\begin{array}{c}\text { Ambient } \\
\text { temperature }\left({ }^{\circ} \mathrm{C}\right)\end{array}$ & 40 & - & - & 5 & 20 & 35 \\
\hline Wind speed(m/s) & 0.5 & 0.5 & 0.61 & 0.45 & 0.45 & 0.2 \\
\hline $\begin{array}{c}\text { Sunshine } \\
\text { strength }\left(W / \mathrm{m}^{2}\right)\end{array}$ & 1000 & 1000 & 900 & 850 & 850 & 1000 \\
\hline $\begin{array}{c}\text { Heat absorption } \\
\text { coefficient }\end{array}$ & 0.9 & 0.9 & 0.5 & 0.9 & 0.9 & 0.9 \\
\hline $\begin{array}{c}\text { Radiation } \\
\text { coefficient }\end{array}$ & 0.9 & 0.9 & 0.6 & 0.9 & 0.9 & 0.9 \\
\hline $\begin{array}{c}\text { Allowable } \\
\text { temperature of } \\
\text { conductor }\left({ }^{\circ} \mathrm{C}\right)\end{array}$ & 70 & 90 & 70 & $15 \sim 100$ & $30 \sim 120$ & $50 \sim 120$ \\
\hline
\end{tabular}

\section{Influence Analysis of Parameters on Dynamic Management of Current-carrying Capacity}

Take conductor type LGJ-240/40 as sample, temperature of the conductor is maximum $70^{\circ} \mathrm{C}$, wind speed is $0.5 \mathrm{~m} / \mathrm{s}$, conductor type is LGJ-240/40, D=21.66mm, $\mathrm{Rd}=0.1209(\Omega / \mathrm{m})$, and describe calculation result of maximum current-carrying capacity under different operation environment.

Influence Analysis of Ambient Temperature on Current-carrying Capacity. When wind speed is $0.5 \mathrm{~m} / \mathrm{s}$ and sunshine strength is $1000 \mathrm{~W} / \mathrm{m}^{2}$, influence of ambient temperature about current-carrying capacity of the conductor is shown in figure 1.

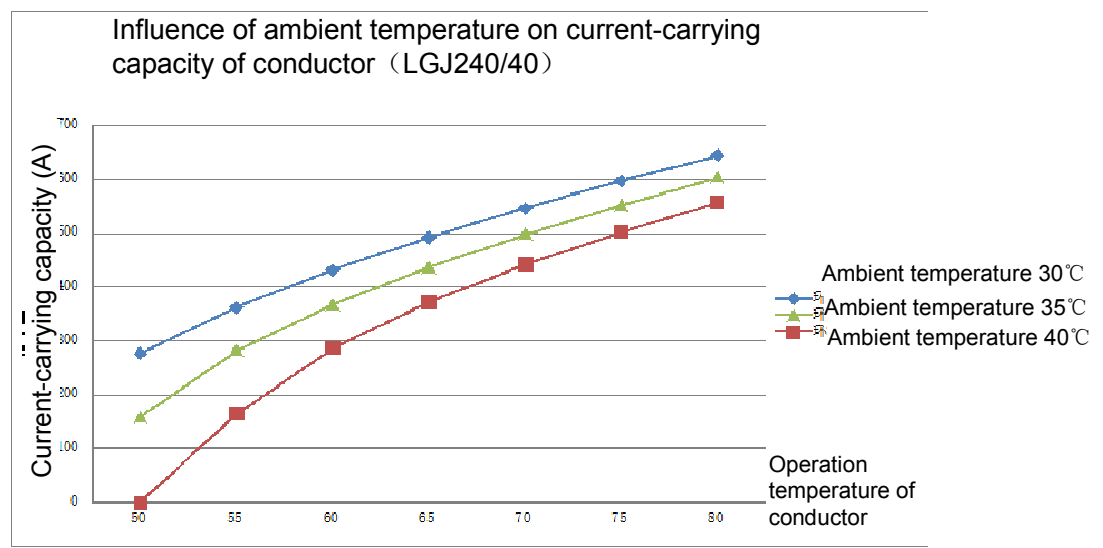

Fig. 1.Influence of ambient temperature on current-carrying capacity

Seen from figure 1: when wind speed is $0.5 \mathrm{~m} / \mathrm{s}$, sunshine strength is $1000 \mathrm{~W} / \mathrm{m}^{2}$, current-carrying capacity under heat balance at ambient temperature lower than $40^{\circ} \mathrm{C}$ and conductor temperature of $70^{\circ} \mathrm{C}$ is improved to 546A from $400 \mathrm{~A}$; when operation temperature of the conductor is fixed and wind speed is fixed, lower is ambient temperature, greater is current-carrying capacity. Current-carrying capacity at ambient temperature of $30^{\circ} \mathrm{C}$ is improved 20 24\% compared that at $40^{\circ} \mathrm{C}$.

Influence of Sunshine Strength on Current-carrying Capacity. When the wind speed is $0.5 \mathrm{~m} / \mathrm{s}$ and ambient temperature is $40^{\circ} \mathrm{C}$, influence of ambient temperature about current-carrying capacity of the conductor is shown in figure 2. 


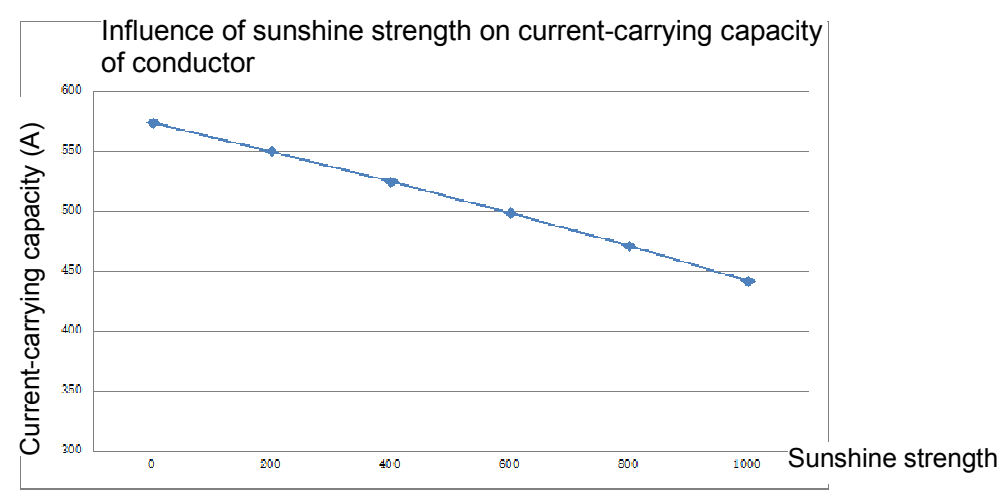

Fig. 2. Influence of sunshine strength on current-carrying capacity

Seen from figure 2: when ambient temperature of the conductor and wind speed are fixed, lower is sunshine strength, greater is current-carrying capacity. When sunshine strength drops down to 200 $\mathrm{W} / \mathrm{m}^{2}$ from $1000 \mathrm{~W} / \mathrm{m}^{2}$, allowable maximum current-carrying capacity of the conductor is improved $24.4 \%$.

Influence of Wind Speed on Current-carrying Capacity of Conductor. When sunshine strength is $1000 \mathrm{~W} / \mathrm{m}^{2}$ and ambient temperature is $40^{\circ} \mathrm{C}$, influence of ambient temperature about current-carrying capacity of the conductor is shown in figure 3.

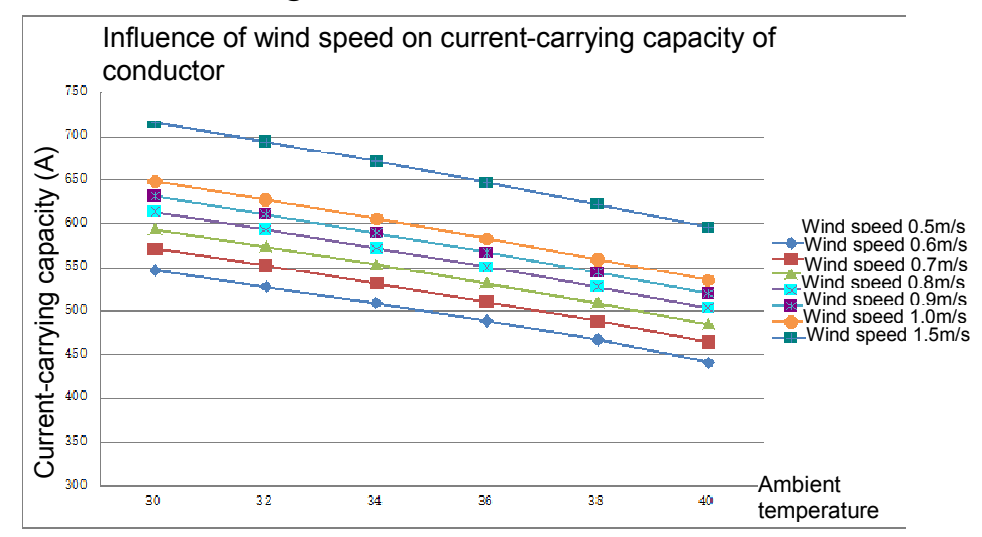

Fig. 3. Influence of wind speed on current-carrying capacity of conductor

Seen from figure 3: current-carrying capacity of the conductor under heat balance is improved to $534 \mathrm{~A}$ when wind speed is $1.0 \mathrm{~m} / \mathrm{s}$ from $400 \mathrm{~A}$ when that is $0.5 \mathrm{~m} / \mathrm{s}$; when operation temperature of the conductor, ambient temperature and sunshine strength are fixed, greater is wind speed, greater is current-carrying capacity. If wind speed is improved one time, allowable current-carrying capacity of the conductor will improve $35 \%$.

\section{Influence of heat dissipation and heat absorption coefficient on current-carrying capacity of conductor.}

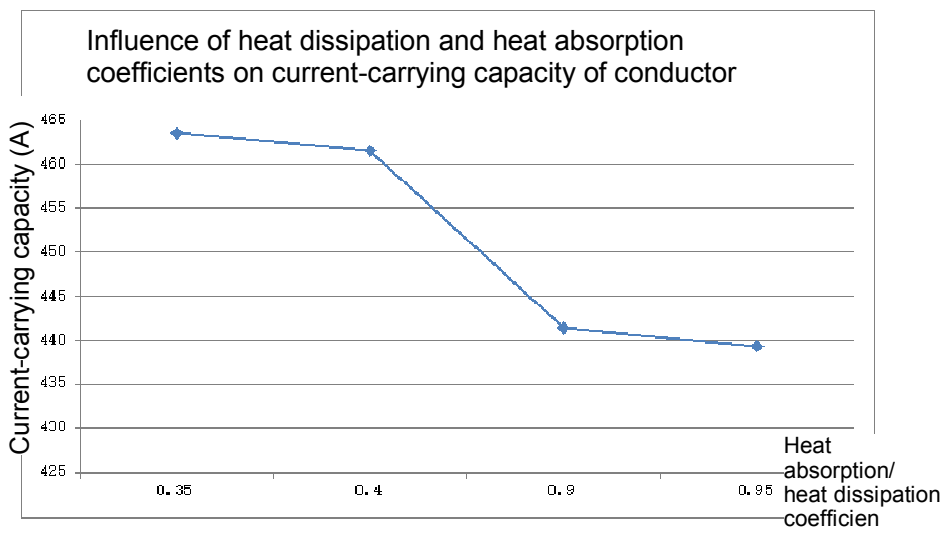

Fig. 4. Influence of heat dissipation and heat absorption coefficient on current-carrying capacity of conductor 
According to regulation of Specification, radiation heat dissipation coefficient on surface of the conductor is $0.23 \sim 0.43$ for the new wire, it is $0.9 \sim 0.95$ for the old wire or the wire coated with black anti-corrosion agent, heat absorption coefficient on surface of the conductor is $0.35 \sim 0.46$ for the bright new wire, it is $0.9 \sim 0.95$ for the old wire; seen from figure 4, allowable maximum current-carrying capacity between the old wire and the new wire is about $20 \mathrm{~A}$ at certain environment parameters. Influence of the radiation heat dissipation coefficient and the heat absorption coefficient on calculation result of the current-carrying capacity is not great.

\section{Comparison between IEEE calculation method and our specification}

The method provided in IEEE is mainly used to calculate temperature of the conductor when current of the conductor is already known or calculate allowable maximum current at given maximum temperature of the conductor. Its main principle is thermal balance and calculation formula of its stable current-carrying capacity is 1 .

In which, calculation formula of radiation heat dissipation power $W_{R}$ is same but calculation formula of convection heat dissipation $W_{F}$ in IEEE is slightly different to the specification, besides wind speed, IEEE specification also considers influence of wind direction, temperature and altitude on air density and air viscosity.

$$
\begin{gathered}
W_{F 1}=\left[1.01+0.0372\left(1000 D \rho V_{w} / \mu_{f}\right)^{0.52}\right] k_{f} K_{\text {angle }}\left(\theta_{d}-\theta_{a}\right) \\
W_{F 2}=\left[0.0119\left(1000 D \rho V_{w} / \mu_{f}\right)^{0.6}\right] k_{f} K_{\text {angle }}\left(\theta_{d}-\theta_{a}\right)
\end{gathered}
$$

In which, $\rho$ is air density, $V_{w}$ is wind speed, $\mu_{f}$ is heat conduction rate of air, $k_{f}$ is heat conduction rate of air, $K_{\text {angle }}$ is wind direction factor.

Calculation formula of the sunshine heat absorption $W_{S}$ in IEEE is slightly different to the specification. IEEE also considers influence of environment cleanness degree, days and sun inclination angle of sun at different hour every day, intrusion effective angle, height angle and altitude.

$$
W_{S}=\alpha \cdot K_{S} \cdot J \cdot D \cdot \sin \gamma
$$

In which, $\alpha$ is surface heat absorption coefficient of the conductor, $J$ is light heating heat of unit area, $D$ is diameter of the conductor, $K_{S}$ is correction factor of heat height, $\gamma$ is effective intrusion angle of sun light.

The inclination angle of sun light and the hour angle is considered in IEEE calculation, $\delta$ is the inclination angle of sun light, $\delta=23.4583 \cdot \sin \left(\frac{284+N}{365} \cdot 360\right), \mathrm{N}$ means no day in one year. $\omega$ is hour angle, $\omega=(t-12) \times 15^{\circ}$

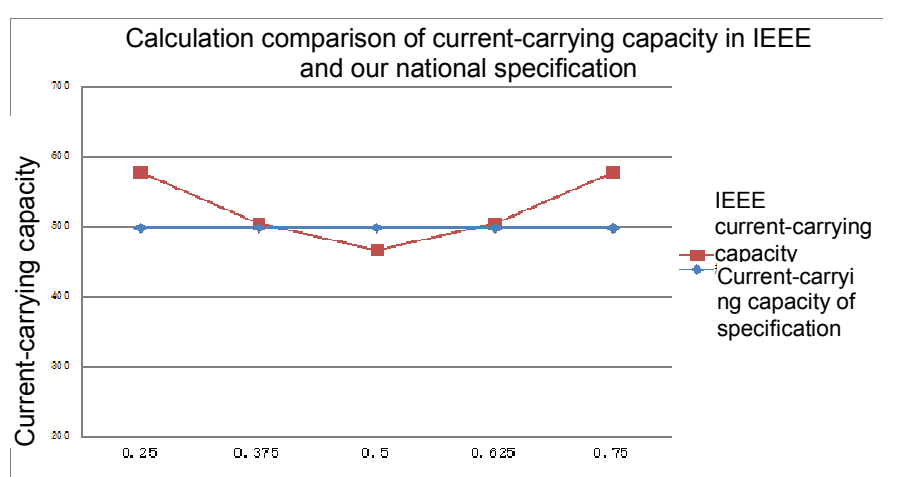

Fig. 5.Comparison of current-carrying capacity of conductor in IEEE and specification in our country

Current-carrying capacity in IEEE and calculation in Specification are deduced based on heat balance principle, they are consistent for calculation of the radiation heat dissipation; for convection 
heat dissipation, calculation of IEEE considers influence of wind direction and altitude, calculation result is slightly less than calculation result of the specification; for sunshine heat absorption, valve specified in Specification is $1000 \mathrm{~W} / \mathrm{m}^{2}$, and influence of latitude of the conductor, time, altitude and route are considered in IEEE, calculation results are changed following above factors as can be seen in fig.5.

Take one of overhead transmission lines in Qinghai as sample, and take monitoring data of the line on May 3. It is shown in fig 6, its ambient temperature is $1-20^{\circ} \mathrm{C}$, wind speed is $0.5-4.6 \mathrm{~m} / \mathrm{s}$ and sunshine strength is $0-800 \mathrm{~W} / \mathrm{m}^{2}$.
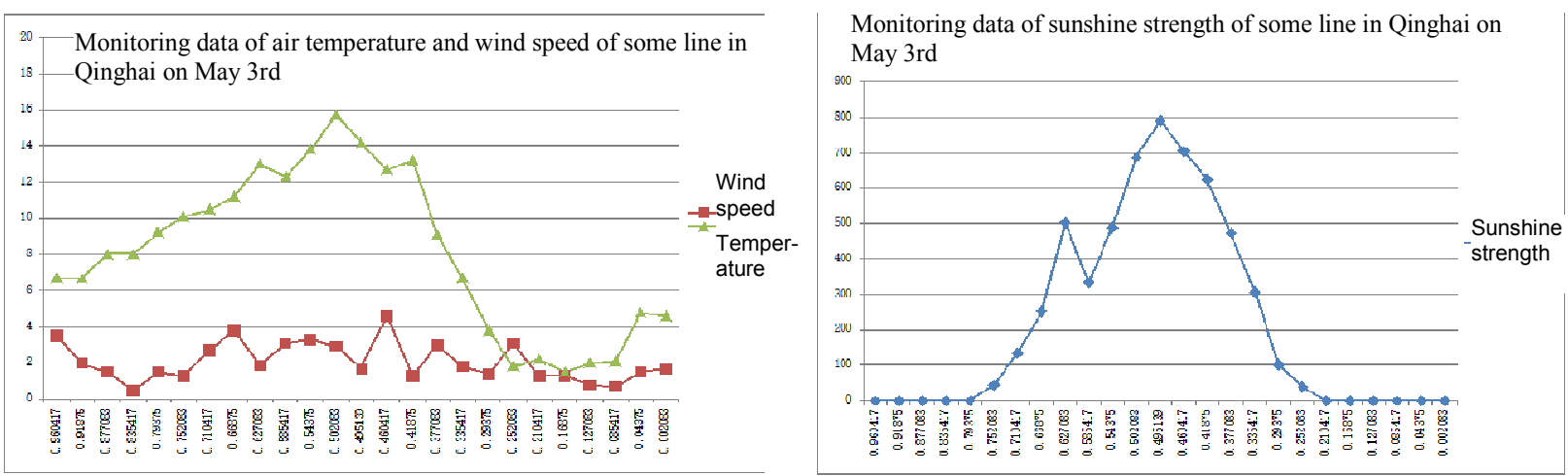

Fig. 6. Air temperature, wind speed and Sunshine strength monitoring data of some line in Qinghai on May 3rd

\section{Conclusion}

The sensitivity of boundary conditions during dynamic management of current-carrying capacity of the overhead conductor is analyzed through calculation, conclusions are shown as following:

Ambient temperature, wind speed, sunshine strength and own parameters of the conductor have influence on allowable maximum current-carrying capacity of the conductor, in which influence of wind speed on current-carrying capacity is great;

Occurrence possibility in sunshine strength of $1000 \mathrm{~W} / \mathrm{m}^{2}$ and wind speed of $0.5 \mathrm{~m} / \mathrm{s}$ specified in the specification is very low. There is certain tolerance when value taken according to regulation is used to calculate current-carrying capacity.

It is convenient to apply Specification for control of the maximum allowable current-carrying capacity during long term operation. For dynamic management of current-carrying capacity in some time section, find out hidden capacity, it shall apply IEEE calculation.

\section{References}

[1] Peng Xiangyang. Analysis on the carrying capacity safety margin and related parameters sensitivity of overhead transmisson lines in Guangdong power grid[J] Southern Grid Technology, 2013(7)6:24-30

[2] Wang Lishen, Comparison of calculating methods of current carrying capacity of overhead lines[J] Power Journal, 2011(26) 5:383-387

[3] Zhang Qiping, Qian Zhiyin. Study on real-time dynamic capacity-increase of transmission lines[J] Grid Technology, 2005 (29) 19:18-21

[4] Han Fang, Xu Qingsong, Hou Wei, Wang Menglong. Application of dynamic current-carrying capacity calculaiton method in overhead conductor[J] Power Construction, 2008 (29) 1:39-43

[5] Dai Yuan, Nie Song, Cheng Yangchun, Wang Yangran. Review of ampacity computation model of transmission line' s dynamic capacity-increase[J] Guangdong Power, 2012 (25) 11:51-56 [6] Zhang Hui, Han Xueshan, Wang Yanling. Analysis on current carrying capacity of overhead lines Bejing operated[J] Grid Technology, 2008 (32) 14:31-35 
[7] Peng Xiangyang, Zhou Huamin, Zheng Xiaoguang, Cheng Qicheng, Lin Shenghong. Study on raising transmission capability of overhead transmission line in special operation condition[J]. China Power 2010 (43) 1:40-42

[8] Xu Qingsong, Ji Hongxian, Hou Wei, Wang Menglong. The novel technique of transmission line' s capacity increase ny means of monitoring conductor' s temperature[J]. Grid Technology 2006(30):171-176

[9] Dai Yuan, Cheng Yangchun, Zhong Wanli, Lin Jiedong etc Dynamic capacity expansion technology of high voltage overhead power transmission line[M]. China power press, Beijing 2013 [10] Zhang Qiping, Qian Zhiyin. Capacity expansion technology of power transmission line [M]. China power press. Beijing 2007 